Plant Tissue Cult. \& Biotech. 25(2): 165-179, 2015 (December)

$\overline{\mathrm{PTC \& B}}$

\title{
Micropropagation and Assessment of Genetic Stability of In Vitro Raised Jojoba (Simmondsia chinensis Link.) Plants Using SCoT and ISSR Markers
}

\author{
S. A. Bekheet, A.M.M. Gabr*, A.A. Reda and M.K. El-Bahr \\ Department of Plant Biotechnology, National Research Centre, 33 El Bohouth St., \\ Dokki, 12622, Giza, Egypt
}

Key words: Simmondsia chinensis, Micropropagation, Genetic stability, Sequence repeat analyses

\begin{abstract}
This study is aimed at developing an efficient method for micropropagation of true-to-type jojoba plants. Nodal segments were used for in vitro shoots proliferation. Among three concentrations of BA used for multiplication, $1 \mathrm{mg} / \mathrm{l}$ BA gave the highest number of shoots. To enhance growth of shoots, combinations of BA and $\mathrm{Kn}$ were investigated. The greater value of shoot length and the maximum number of nodes were observed in the medium containing $1 \mathrm{mg} / \mathrm{l} \mathrm{BA}+1.5 \mathrm{mg} / \mathrm{l} \mathrm{Kn}$. Among different medium used to increase the rate of multiplication, the maximum number of shoots was recorded at $1 / 2 \mathrm{MS}+$ Gamborg B5 (B5) vitamins $+2 \mathrm{mg} / \mathrm{l} \mathrm{Kn}+10 \mathrm{mg} / \mathrm{l}$ adenine sulphate (AS). Rooting was obtained upon supplementation of $1 / 2$ Woody Plant Medium (WPM) with $1 \mathrm{mg} / \mathrm{l} \mathrm{IBA}$. Acclimation was achieved by transplanting rooted plantlets into pots containing peat moss and vermiculite. Start codon targeted (SCoT) and intersimple sequence repeat (ISSR) analyses were carried out to assess the genetic fidelity of micropropagated plantlets. All banding profiles of the two analyses from micropropagated plants were monomorphic and similar to the mother plant. Hence, this protocol can be employed for commercial micropropagation of jojoba without the risk of losing genetic stability.
\end{abstract}

\section{Introduction}

Jojoba (Simmondsia chinensis Link.) has become a promising industrial crop because of the important commercial applications of its seed oil. The extracted oil

*Author for correspondence: <a_m_gabr2@yahoo.com>. 
is used in a variety of products, including lubricants, pharmaceuticals, and cosmetics. Jojoba is dioecious; the female plants produce seed from flowers pollinated by the male plants. Thus, female plants are commercially more important for seed production. For commercial yield only $10 \%$ male population is required. Because Jojoba is heterogeneous and highly variable as a result of its cross-pollination, a small proportion (less than 1\%) of the plant population originating from seeds has the potential of yielding economically acceptable yields. Hence, the best method for improvement of jojoba cultivation is the selection of plants with desirable characteristics and to propagate asexually. Rooting of stem cuttings is the easiest and commonly used asexual propagation method in jojoba. The best cutting material is the current year growth that is semi-hardened (Prat et al. 1998). Despite success in conventional vegetative propagation, the amount of shoot material for cuttings is limited and rooting is a lengthy process. Because relatively large number of jojoba plants is planted per hectare and nursery-produced plants are expensive, plant material costs are a significant part of the overall expense of establishing a commercial planting with high yielding clones.

Therefore, propagation of jojoba by tissue culture has been undertaken here as a potential alternative to propagation from seed or by conventional vegetative methods. Micropropagation offers opportunities for production of elite plants from the selected stock plant of jojoba in a short time independent of the season. Multiple shoots can be produced in vitro and these can be developed into plantlets by regenerating their roots. Thus a single explant source, shoot tip or nodal segment could conceivably provide thousands of new true-to-type plantlets per year i.e., those plants that are genetically similar to the parental stock and that could potentially maintain the genetic line. Moreover, jojoba plants derived from tissue culture grow more vigorously than seedlings or rooted cuttings, and yield a significantly larger population after first year growth. Some reports on in vitro propagation using various explants such as auxiliary buds (Chaturvedi and Sharma 1989, Llorente and Apostolo 1998), nodal explants (Tyagi and Prakash 2004, Hegazi et al. 2014) and shoot tips (Sardana and Batra 1998) are available. In vitro rooting percentage ranged from 20 and 95\% depending on the clone and the specific trial. The highest rate of rooting occurred on the medium containing IBA (Elhag et al. 1998). Acclimation of in vitro produced micropropagated jojoba plantlets for transfer to field has been difficult, since the necessary high humidity environment can result in lack of aeration and death of the root system (Chaturvedi and Sharma 1989), or because the leaves produced in the culture are of reduced size (Lee 1988). 
Because jojoba is a slow growing plant, it needs to be selected on the basis of high yield potential as well as its ability for successful establishment through vegetative propagation. In this respect, molecular biology techniques are of great help for characterization of jojoba germplasm because the genetic information provided by morphological characters is often limited and the expression of quantitative traits is subjected to environmental influence. Moreover, molecular markers can be used for characterization and early detection of genetic stability of the in vitro propagated plants. In this context, random amplified polymorphic DNA (RAPD) and inter simple sequence repeat (ISSR) markers were screened to test the genetic integrity of jojoba (Kumar et al. 2011). Start codon targeted (SCoT) polymorphism, the novel marker system based on the short conserved region in plant genes surrounding the ATG translation start codon (Collard and Mackill 2009) has been successfully employed indetermining the genetic diversity analysis and finger printing the population (Mulpuri et al. 2013, Guo et al. 2014, Satya et al. 2015). A better analysis of genetic stability of in vitro raised plantlets can be made by using a combination of two types of markers that amplify different regions of the genome (Martins et al. 2004). The objective of the present study is to develop a suitable protocol for micropropagation of jojoba and assess the genetic stability of in vitro grown propagules based on the study of SCoT and ISSR markers.

\section{Materials and Methods}

Female jojoba plants are propagated through cuttings in farm of Egyptian Natural Oil Company that their origin plants were introduced from USA. The latter stem segments were used as plant materials. About one hundred nodal segments taken from new branches were washed by running tap water for 30 min and then dipped in ethanol $70 \%$ for $30 \mathrm{sec}$. The explants were then sterilized with mercuric chloride solution (0.2\%) for $10 \mathrm{~min}$. After sterilization, the explants were rinsed in sterilized distilled water (three times) to remove all traces of the disinfectants. All steps of the sterilization have been done under aseptic conditions using laminar airflow cabinet. The explants were aseptically cultured on solidified MS supplemented with $0.5 \mathrm{mg} / \mathrm{l} \mathrm{BA}$ based on results of our primary experiments, keeping one explant per tube. Proliferated shoots (Fig. 1A) were used for multiplication.

To investigate the effect of BA concentrations on the ability of shoot multiplication through formation of adventitious shoot buds of jojoba, the proliferated shoots were divided. Single uniform shoots $(1 \mathrm{~cm}$ length) were vertically cultured. 
In order to examine howcombination of BA and kinetin $(\mathrm{Kn})$ affects shoot multiplication of jojoba, single uniform shoots $(1 \mathrm{~cm}$ length) were cultured on MS supplemented with two concentrations of both cytokinins as follows:

$1 \mathrm{mg} / \mathrm{l} \mathrm{BA}+1 \mathrm{mg} / \mathrm{l} \mathrm{Kn}, 1 \mathrm{mg} / \mathrm{l} \mathrm{BA}+1.5 \mathrm{mg} / \mathrm{l} \mathrm{Kn}$

$1.5 \mathrm{mg} / \mathrm{l} \mathrm{BA}+1 \mathrm{mg} / \mathrm{l} \mathrm{Kn}, 1.5 \mathrm{mg} / \mathrm{l} \mathrm{BA}+1.5 \mathrm{mg} / \mathrm{l} \mathrm{Kn}$

To assess the effect of growth regulators and adenine sulfate (AS) in combination with culture medium on shoot proliferation of jojoba growing in vitro, the following treatments were undertaken:

$3 / 4 \mathrm{MS}+2 \mathrm{mg} / \mathrm{l} \mathrm{Kn}+10 \mathrm{mg} / \mathrm{l} \mathrm{AS}, 3 / 4 \mathrm{MS}+\mathrm{B} 5$ vitamins + $2 \mathrm{mg} / \mathrm{l} \mathrm{Kn}+10 \mathrm{mg} / \mathrm{l} \mathrm{AS}$

$1 / 2 \mathrm{MS}+2 \mathrm{mg} / \mathrm{l} \mathrm{Kn}+10 \mathrm{mg} / \mathrm{l} \mathrm{AS}, 1 / 2 \mathrm{MS}+\mathrm{B} 5$ vitamins + $2 \mathrm{mg} / \mathrm{l} \mathrm{Kn}+10 \mathrm{mg} / \mathrm{l} \mathrm{AS}$.

WPM+ 2 mg/l Kn + 10 mg/l AS, B5 + 2 mg/l Kn + 10 mg/l AS.

Number of shoots per explant, length of primary shoots $(\mathrm{cm})$ and number of nodes per primary shoot were recorded after six weeks of culturing.

Cultures were normally incubated at $25 \pm 2^{\circ} \mathrm{C}$ and $16 \mathrm{hrs}$ photoperiod provided by white fluorescent tubes (3000 lux light intensity). Experiments were run in completely randomized design and data were statistically analyzed using standard error (SE) according to the method described by Snedecor and Cochran (1967).

To assess the effect of IBA on rooting of jojoba shoots grown in vitro, different concentrations $(0.5,1.0$ and 1.5) of IBA were added to half strength of MS or half strength of WPM. The elongated shoots $(4 \mathrm{~cm})$ were individually cultured in $25 \times 150 \mathrm{~mm}$ culture tubes containing the rooting media. Cultures were incubated for one week in the dark and then transferred into to half strength of MS or half strength of WPM without IBA and incubated at 16/8 hrs light/dark condition for seven weeks. Rooting percentages were recorded at the end of the two incubation periods (eight weeks).

Tissue culture media were solidified with $0.7 \%$ agar, supplemented with 30 $\mathrm{g} / \mathrm{l}$ sucrose and adjusted to $\mathrm{pH} 5.8$ before autoclaving at $121^{\circ} \mathrm{C}$ and $1.5 \mathrm{Ib} / \mathrm{M}^{2}$ for $25 \mathrm{~min}$.

The genomic DNA of jojoba was isolated from young leaf tissue of both in vitro (second, third and fourth subcultures) and ex vitro grown mother plants following the steps of CTAB (hexadecyltrimethyl ammonium bromide) protocol (Porebski et al. 1997).

A set of four random primers (AM1, AM2, AM5 and AM7) was used in the detection of polymorphism among mother plants and different subcultures. SCoT-PCR was carried out according to the procedure given by Collard and Mackill (2009). The amplification reaction was carried out in $25 \mu \mathrm{l}$ reaction volume containing 1X PCR buffer, $1.5 \mathrm{mM} \mathrm{MgCl}$, $2 \mathrm{mM}$ dNTPs, 1 U Taq DNA 
polymerase and $25 \mathrm{ng}$ templates DNA and $1 \mu \mathrm{M}$ primer from each of random primers. PCR amplification was performed in a Biometera Uno thermal cycles programmed to fulfill 40 cycles after an initial denaturation cycle for $5 \mathrm{~min}$ at $94^{\circ} \mathrm{C}$. Each cycle consisted of a denaturation step at $94^{\circ} \mathrm{C}$ for $1 \mathrm{~min}$, an annealing step at $36^{\circ} \mathrm{C}$ for $1 \mathrm{~min}$, and an elongation step at $72^{\circ} \mathrm{C}$ for $1.5 \mathrm{~min}$. The primer extension segment was extended to $7 \mathrm{~min}$ at $72^{\circ} \mathrm{C}$ in the final cycle. The amplification products were resolved by electrophoresis in a $1.5 \%$ agarose gel containing ethidium bromide $(0.5 \mu \mathrm{g} / \mathrm{ml})$ in $1 \mathrm{X}$ TBE buffer at 90 volts. Gel was photographed under UV light with Tracktel GDS-2 gel documentation system. The size of the amplification products was estimated from VC 100 bp plus DNA ladder.

ISSR scorable primers (HB9, HB10, HB11 and HB12) screened for PCR amplification. PCR was performed in $25 \mu \mathrm{l}$ reaction volume containing 1X PCR buffer, $1.75 \mathrm{mM} \mathrm{MgCl}$, $5 \mathrm{mM}$ of each dNTPs, $40 \mu \mathrm{M}$ oligonucleotide primer from each of the ISSR primers, $25 \mathrm{ng}$ genomic DNA and $1 \mathrm{U}$ of Taq DNA polymerase. However, the optimized PCR conditions for ISSR amplifications consisted of an initial denaturation step for $5 \mathrm{~min}$ at $94^{\circ} \mathrm{C}$, followed by 35 cycles each of $20 \mathrm{~s}$ at $94^{\circ} \mathrm{C}$ for denaturation, $60 \mathrm{sec}$. at $50^{\circ} \mathrm{C}$ for annealing, $90 \mathrm{sec}$ at $72^{\circ} \mathrm{C}$ for extension. The final extension was done for $7 \mathrm{~min}$ at $72^{\circ} \mathrm{C}$. The PCR products were separated by electrophoresis in a $2.0 \%$ agarose gel containing ethidium bromide $(0.5 \mu \mathrm{g} / \mathrm{ml})$ in $1 \mathrm{X}$ TBE buffer at 90 volts. Gel was photographed under UV light with Tracktel GDS-2 gel documentation system. The size of the amplification products was estimated from the $100 \mathrm{bp}$ DNA ladder.

For adaptation to the free-living conditions, the rooted plantlets were taken out from the culture tubes; the adhering agar was then removed in running tap water and the plantlets disinfected by soaking in benlate solution $(1 \mathrm{~g} / \mathrm{l})$ for 20 min. Then plantlets were transplanted into plastic pots $(10 \mathrm{~cm}$ diameter $)$ containing peat moss and vermiculite $(1: 1)$. The pots were covered with clear polyethylene bags which were sprayed with water to maintain a high relative humidity. Plantlets were watered with distilled water. Water supply was monitored very carefully during the first month of acclimation. Covers were gradually removed within six weeks.

\section{Results and Discussion}

To investigate the effect of BA on in vitro proliferation of adventitious shoot buds and development of primary shoots of jojoba, three concentrations of BA i.e., 0.5, 1.0 and $1.5 \mathrm{mg} / \mathrm{l}$ were examined. Data revealed that the parameters under study expressed as mean \pm SE were significantly affected by BA concentrations. The data also indicated that medium containing $1 \mathrm{mg} / \mathrm{l}$ BA recorded the highest 
number (7.90) of shoots per explants (Table 1 and Fig. 1B). However, no shoot proliferation was observed on hormone-free medium. Otherwise, the maximum length of primary shoot $(3.5 \mathrm{~cm})$ was attained at MS hormone free medium, while the minimum one $(1.80 \mathrm{~cm})$ was attained by the medium containing 1.5 $\mathrm{mg} / \mathrm{l} \mathrm{BA}$. Also, the maximum number of nodes per primary shoots (3.00) was produced on MS hormone-free medium. It was noticed that some vitrified shoots were observed in the medium containing $1.5 \mathrm{mg} / \mathrm{l} \mathrm{BA}$.
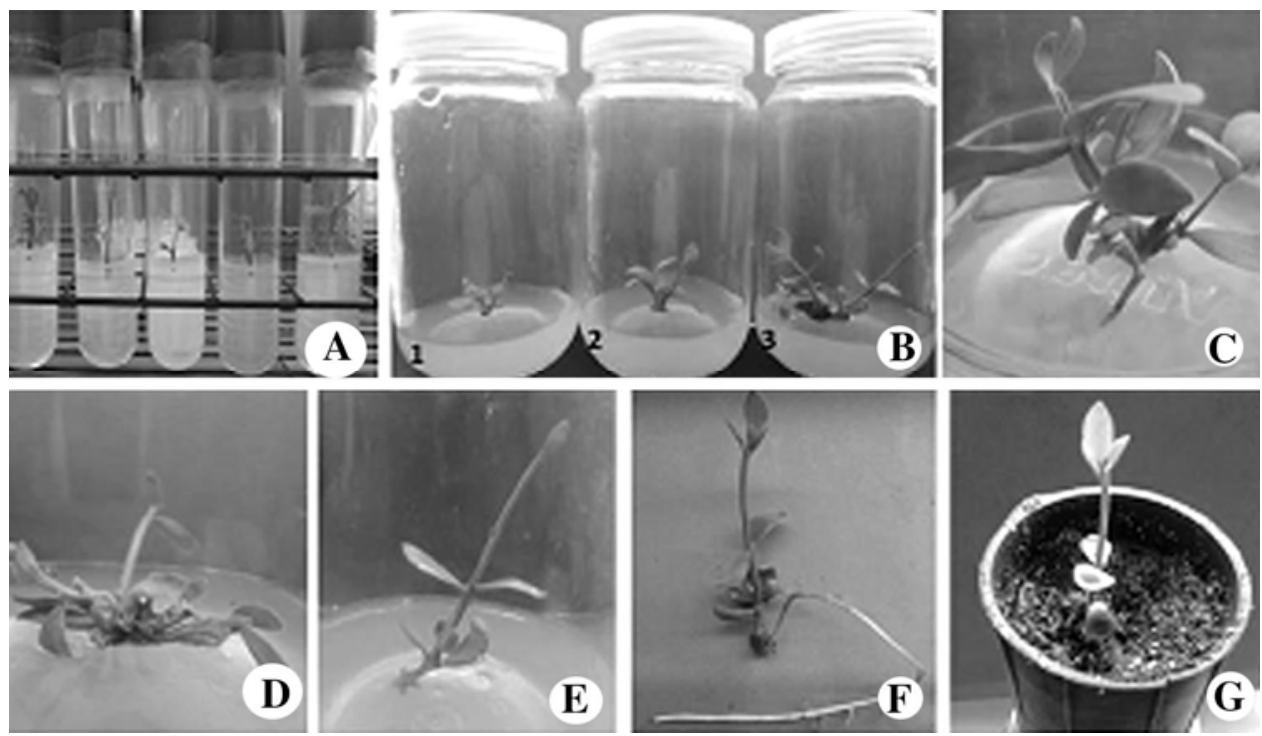

Fig. 1. (A) In vitro proliferation of jojoba shoots using MS supplemented with $0.5 \mathrm{mg} / \mathrm{l} \mathrm{BA}$. (B). Multiplication of shoots on MS containing $1 \mathrm{mg} / \mathrm{l} \mathrm{BA}$ after two [1], four [2] and six weeks [3] of culturing. (C). Shoots growing on the medium containing $1 \mathrm{mg} / \mathrm{l} \mathrm{BA}$ $+1.5 \mathrm{mg} / \mathrm{l} \mathrm{Kn}$. (D). The highest primary shoots grown on half strength of MS containing $2 \mathrm{mg} / \mathrm{l} \mathrm{Kn}+10 \mathrm{mg} / \mathrm{l} \mathrm{AS}$. (E). Elongation of micro-shoots using MS hormone free medium. (F). Root formation on half strength of WPM with $1 \mathrm{mg} / \mathrm{l}$ IBA. (G) Adapted plantlet of jojoba to free living conditions using transplanting medium containing a mixture of peat moss and vermiculite.

Generally, the types and concentration of cytokinin, culture media, explants and genotypes are the most important factors affecting the in vitro multiplication of plant propagules. In the present study, reasonable shoot proliferation was observed from single shoots of the female jojoba plants on MS supplemented with BA. Addition of BA in different concentrations had significant positive effects on shoot multiplication. Otherwise, the number of proliferated shoots increased as the incubation period increased. However, the length of primary shoots and the number of nodes per primary shoot was negatively affected when the culture medium was supplemented by BA. All the examined concentrations 
of BA produced short were primary shoots and a smaller number of nodes per primary shoot than those observed in MS. The results of the present study are in agreement with those reported by Llorente and Apostolo (1998). They reported that there was a 4.6 -fold increase in shoot numbers of jojoba at 30 days on MS supplemented with $1 \mathrm{mg} / \mathrm{l} \mathrm{BA}$. The results also supported the findings of Abud and Lugo (1983) who obtained after six weeks new shoots, bearing 15 nodes from stem node explants cultured on MS containing BA. BA alone has a significant role in increasing the number of shoots from jojoba explants as compared to any other cytokinin. Agrawal et al. (2002), Prakash et al. (2003) and Tyagi and Prakash (2004) also found a significant increase in the number of shoots by BA during in vitro multiplication of jojoba, while, Bashir et al. (2007a) reported that BA at the rate of $2.5 \mathrm{mg} / \mathrm{l}$ caused the earliest sprouting of buds and produced the longest primary shoot, the maximum number of nodes per primary shoot. BA at the rate of $5 \mathrm{mg} / \mathrm{l}$ produced the maximum number of shoots per explant.

Table 1. Effect of different concentrations of BA on in vitro shoot proliferation of jojoba. Mean $\pm S E, n=20$.

\begin{tabular}{lccc}
\hline Culture medium & $\begin{array}{c}\text { Number of } \\
\text { proliferated shoots }\end{array}$ & $\begin{array}{c}\text { Length of primary } \\
\text { shoots }(\mathrm{cm})\end{array}$ & $\begin{array}{c}\text { Number of nodes/ } \\
\text { primary shoots }\end{array}$ \\
\hline MS hormone-free & - & 3.50 & $3.00 \pm 0.40$ \\
MS + 0.5 mg/l BA & $5.00 \pm 0.09$ & 2.50 & $2.60 \pm 0.21$ \\
MS + 1.0 mg/l BA & $7.90 \pm 0.04$ & 2.00 & $2.10 \pm 0.19$ \\
MS + 1.5 mg/l BA & $7.20 \pm 0.08$ & 1.80 & $1.80 \pm 0.29$ \\
\hline
\end{tabular}

This part of study was aimed at investigating the effect of combinations of $\mathrm{BA}$ and $\mathrm{Kn}$ on in vitro shoots multiplication of jojoba. For this purpose, in vitro grown shoots were cultured on MS containing BA (1 and $1.5 \mathrm{mg} / \mathrm{l})$ combined with $\mathrm{Kn}(1$ and $1.5 \mathrm{mg} / \mathrm{l})$. Results presented in Table 2 reveal that BA in combination with different levels of $\mathrm{Kn}$ obviously promoted the length of primary shoots and number of nodes per primary shoot. The greater value of primary shoots length $(4.60 \mathrm{~cm})$ was observed in the medium containing $1 \mathrm{mg} / \mathrm{l}$ $\mathrm{BA}+1.5 \mathrm{mg} / \mathrm{l} \mathrm{Kn}$ (Fig. -C). However, the maximum number of nodes per primary shoots (3.70) was attained in the medium containing $1.5 \mathrm{mg} / \mathrm{l} \mathrm{BA}+1$ $\mathrm{mg} / \mathrm{l} \mathrm{Kn}$ (Table 2). In contrast, addition of $\mathrm{Kn}$ to the BA-containing medium led to a reduced number of shoots per explants, since BA alone (previous experiment) gave the high numbers of shoot proliferation. The highest value of shoots proliferation (7.00) in this experiment was recorded in MS + $1.5 \mathrm{mg} / \mathrm{l} \mathrm{BA}+1 \mathrm{mg} / \mathrm{l}$ $\mathrm{Kn}$. It is important here to mention that there was no vitrification in any of these treatments. 
In the present investigation, the media containing BA in combination with Kn proved to be better in enhancing both the length of primary shoots as well as the number of nodes per primary shoot. It appears that Kn was driving the generation of longer primary shoots and a higher number of nodes. These results are partially in agreement with those reported by Kacker et al. (1993). These authors mentioned that axillary shoots of jojoba were produced in vitro on MS supplemented with $0.5 \mathrm{mg} / \mathrm{l} \mathrm{Kn}$ and $1.0 \mathrm{mg} / \mathrm{l} \mathrm{BA}$ within a month of culture. Llorente and Apostolo (1998), in their study of in vitro propagation of jojoba, stated that shoot growth was significantly greater in BA than Kn treatments. However, Lee (1988) also reported that $\mathrm{Kn}$ as a cytokinin source was inferior to BA when used for in vitro shoot initiation of jojoba. Number of shoots per explant remained greater in response to $\mathrm{BA}$ than that of $\mathrm{Kn}$ due to its prime role in shoot formation. In this context, Bashir et al. (2007b) reported that BA (alone) was found to be better than Kin (alone) or BA $+\mathrm{Kn}$ for in vitro shoot initiation of jojoba. The lower concentration $(5.55 \mu \mathrm{M})$ of BA was found to be more effective for many shoot parameters and the genotype PKJ-3 was the most responsive to in vitro conditions. Recently, the genotypic and $\mathrm{BA}$ and $\mathrm{Kn}$ in combination with NAA, IAA and 2,4-D effects on in vitro nodal segments of jojoba were investigated by Mousa and Bakhashwain (2014). They found that a culture medium supplemented with high BA and IAA concentration enhanced shoot formation of the nodal segments of the four tested jojoba genotypes. The maximum length of regenerated shoots, number of nodes/shoot and number of shoots /explants were obtained on the culture medium MS + $10 \mu \mathrm{M}$ BA + $5 \mu \mathrm{M}$ IAA.

In this experiment, the in vitro growing shoots of jojoba were cultured on three fourth strength of and half strength of MS, B5 and WPM supplemented with different combinations of Kn, AS and B5 vitamins. The data showed that the parameter under study was significantly affected by the media and the supplementations. The combination consisting of B5 vitamins $+2 \mathrm{mg} / \mathrm{l} \mathrm{Kn}+10$ $\mathrm{mg} / \mathrm{l} \mathrm{AS}$ had the best positive effect on shoots proliferation. Data also revealed that MS was the best for shoot multiplication of jojoba compared to B5 or WPM. The maximum number of shoots per explant (10.20) was recorded at half strength of MS + B5 vitamins $+2 \mathrm{mg} / \mathrm{l} \mathrm{Kn}+10 \mathrm{mg} / \mathrm{l} \mathrm{AS}$, followed by that of half strength of MS $+2 \mathrm{mg} / \mathrm{l} \mathrm{Kn}+10 \mathrm{mg} / \mathrm{l} \mathrm{AS} \mathrm{(8.80)} \mathrm{(Table} \mathrm{3).} \mathrm{However,} \mathrm{the} \mathrm{lowest}$ number of shoots per explant (5.50) was recorded in the treatment with three fourth strength of MS $+2 \mathrm{mg} / \mathrm{l} \mathrm{Kn}+10 \mathrm{mg} / \mathrm{l} \mathrm{AS}$. Moreover, half strength of MS containing $2 \mathrm{mg} / \mathrm{l} \mathrm{Kn}+10 \mathrm{mg} / \mathrm{l}$ AS gave the highest values of primary shoot length $(3.40 \mathrm{~cm})$ and number of nodes per primary shoots (3.60) (Table 3 and Fig. 1D). 
In the present study, the media containing half strength of MS salts supplemented with B5 vitamins $+2 \mathrm{mg} / \mathrm{l} \mathrm{Kn}+10 \mathrm{mg} / \mathrm{l}$ AS had the best effects on shoots proliferation, length of primary shoots and number of nodes per primary shoots of jojoba growing in in vitro. However, lower shoots proliferation was associated with B5 medium containing $2 \mathrm{mg} / \mathrm{l} \mathrm{Kn}+10 \mathrm{mg} / \mathrm{l} \mathrm{AS}$. These results are accordance with those reported by Llorente and Apóstolo (2013). They mentioned that internodal and apical cuttings of jojoba proliferated on MS containing B5 vitamins and $4.4 \mu \mathrm{M}$ BA. In this respect, MS and B5 media supplemented with a combination of cytokinins (BA, Kn and zeatin) and auxins (NAA, IAA, IBA) have been used for jojoba multiplication in vitro (Agrawal et al. 2002, Bashir et al. 2007a). Mohasseb et al. (2009) stated that MS supplemented with BA and GA3 partially enhanced shoot initiation of jojoba shoot tips. In this context, effects of different types of medium; MS, WPM, B5 and Hildebrandt medium (SH) were studied for in vitro shoot proliferation of mulberry (Niratker

Table 2. Effect of combinations of BA and $\mathrm{Kn}$ on in vitro shoots proliferation of jojoba. Mean $\pm S E, n=20$.

\begin{tabular}{lccc}
\hline $\begin{array}{l}\text { Culture } \\
\text { medium }\end{array}$ & $\begin{array}{c}\text { No. of } \\
\text { proliferated } \\
\text { shoots }\end{array}$ & $\begin{array}{c}\text { Length of } \\
\text { primary } \\
\text { shoots }(\mathrm{cm})\end{array}$ & $\begin{array}{c}\text { No. nodes/ primary } \\
\text { shoots }\end{array}$ \\
\hline MS + 1 mg/l BA + $1 \mathrm{mg} / \mathrm{l} \mathrm{Kn}$ & $6.40 \pm 0.14$ & 3.50 & $3.30 \pm 0.15$ \\
MS + 1 mg/l BA + $1.5 \mathrm{mg} / \mathrm{l} \mathrm{Kn}$ & $6.50 \pm 0.20$ & 4.60 & $3.50 \pm 0.15$ \\
MS + 1.5 mg/l BA + 1 mg/l Kn & $7.00 \pm 0.25$ & 3.30 & $3.70 \pm 0.18$ \\
MS + 1.5 mg/l BA + 1.5 mg/l Kn & $6.20 \pm 0.10$ & 3.20 & $3.60 \pm 0.12$ \\
\hline
\end{tabular}

Table 3. Effect of growth regulators and culture media on shoots multiplication of jojoba. Mean $\pm \mathrm{SE}, \mathrm{n}=20$.

\begin{tabular}{|c|c|c|c|}
\hline $\begin{array}{l}\text { Culture } \\
\text { medium }\end{array}$ & $\begin{array}{c}\text { No. } \\
\text { proliferated } \\
\text { shoots }\end{array}$ & $\begin{array}{c}\text { Length of } \\
\text { primary } \\
\text { shoots }(\mathrm{cm})\end{array}$ & $\begin{array}{c}\text { No. nodes/ } \\
\text { primary } \\
\text { shoots }\end{array}$ \\
\hline $3 / 4 \mathrm{MS}+2 \mathrm{mg} / \mathrm{l} \mathrm{Kn}+10 \mathrm{mg} / \mathrm{l} \mathrm{AS}$ & $7.50 \pm 0.18$ & 2.40 & $2.10 \pm 0.20$ \\
\hline $3 / 4 \mathrm{MS}+\mathrm{B} 5$ vitamins $+2 \mathrm{mg} / \mathrm{Kn}+10 \mathrm{mg} / \mathrm{l} \mathrm{AS}$ & $8.50 \pm 0.30$ & 2.50 & $2.20 \pm 0.17$ \\
\hline $1 / 2 \mathrm{MS}+2 \mathrm{mg} / \mathrm{l} \mathrm{Kn}+10 \mathrm{mg} / \mathrm{l} \mathrm{AS}$ & $8.80 \pm 0.20$ & 3.30 & $2.90 \pm 0.15$ \\
\hline $1 / 2 \mathrm{MS}+\mathrm{B} 5$ vitamins $+2 \mathrm{mg} / \mathrm{l} \mathrm{Kn}+10 \mathrm{mg} / \mathrm{l} \mathrm{AS}$ & $10.20 \pm 0.40$ & 3.40 & $3.60 \pm 0.12$ \\
\hline $\mathrm{WPM}+2 \mathrm{mg} / \mathrm{l} \mathrm{Kn}+10 \mathrm{mg} / \mathrm{l} \mathrm{AS}$ & $7.50 \pm 0.22$ & 2.80 & $2.90 \pm 0.18$ \\
\hline B5 medium + $2 \mathrm{mg} / \mathrm{l} \mathrm{Kn}+10 \mathrm{mg} / \mathrm{l} \mathrm{AS}$ & $6.80 \pm 0.15$ & 2.50 & $2.80 \pm 0.12$ \\
\hline
\end{tabular}

$3 / 4=$ three fourth strength, $1 / 2=$ half strength. 
et al. 2015). Multiple shoots were achieved from invitro raised shoots on all the four different medium supplemented with BAP (1.0 - $1.5 \mathrm{mg} / \mathrm{l})$, NAA (0.25 - 0.5 $\mathrm{mg} / \mathrm{l})$ and GA3 $(0.5 \mathrm{mg} / \mathrm{l})$. MS was found to be the best for shoot induction and high frequency of induced shoots.

In this experiment, microshoots of jojoba grown in in vitro were elongated using MS hormone free medium (Fig. 1E). The elongated shoots then placed in $1 / 2$ MS or half strength of WPM supplemented with $0.5,1.0$ and 1.5 of IBA in an attempt to induce root formation. Our work reveals that rooting was achieved only upon supplementation of half strength of WPM with $1 \mathrm{mg} / \mathrm{l} \mathrm{IBA} \mathrm{(Fig.} \mathrm{1F).}$ White roots began to appear within three weeks. After five weeks of culturing, healthy and long roots were induced. No root formation was observed on other treatments. Successful adaptation (75\%) of jojoba grown in in vitro to free living conditions was obtained by transplanting well rooted plantlets into pots containing equal volumes of peat moss and vermiculite (Fig. 1G). We observed that the most essential requirement for successful transplantation is to maintain the plants under high humidity especially in the first two weeks. The plants showed no morphological differences from those grown in in vivo.

Root formation is a critical stage in micropropagation of jojoba. In vitro root initiation and subsequent plantlet growth depends upon auxins and their concentrations (Roussos et al. 1999); type, strength and supplements of media (Kacker et al. 1993), genotypes (Llorente and Apostolo 1998), cultural conditions and various in vitro techniques (Tyagi and Prakash 2004). In the present study, it was found that transfer of the elongated shoots into a medium containing $1 \mathrm{mg} / \mathrm{l}$ IBA for 7 days and then back into the basic medium induced rooting. Similar procedures have been reported by Meyghani et al. (2005). They mentioned that rooting occurred when in vitro shoots were first treated with $120 \mathrm{mg} / \mathrm{l}$ IBA solution for $24 \mathrm{hrs}$ followed by their transferon to MS without plant growth regulators. Comparable results were also reported by Reda (2003). However, Khanam et al. (1999) reported that successful rooting was obtained from shoot bunches of jojoba on MS supplemented with 0.2 - $2.0 \mathrm{mg} / \mathrm{l} \mathrm{BA}, 2.0 \mathrm{mg}$ IBA mg/l and $5000 \mathrm{mg} / \mathrm{l}$ activated charcoal. In this context, attempts were made to root micropropagated shoots of jojoba on various media (half strength of MS or MS with or without IAA, NAA and IBA) (Elhag et al. 1998). The highest rate of rooting occurred on the MS containing $3 \mathrm{mg} / \mathrm{l} \mathrm{IBA}$.

The success of in vitro method in plant propagation depends not only on the number of the plantlets produced, but also on survival rate upon transfer to nursery and field conditions. The transition of jojoba plantlets from in vitro to ex vitro conditions (acclimatization) can be difficult. High humidity in the in vitro culture conditions should be gradually reduced to allow plantlets to develop 
normal cuticle and stomata and to avoid dehydration during acclimation (Hazarika 2003). The percentage survibality (75) in the present work may be due to the well-developed cuticle and root system. Also, partial defoliation of plantlets at the time of transplantation was beneficial.

In order to assess the genetic fidelity of micropropagated jojoba plantlets, RAPD and ISSR fingerprinting of randomly-selected in vitro plants and their donor mother plant was carried out. A total of 4 primers clear and reproducible bands. The four primers produced 19 distinct and scorable bands, with an average of 4.75 bands per primer. No polymorphism was detected with the four primers during the SCoT analysis of in vitro raised clones (Fig. 2, Table 4). All banding profiles from micropropagated plants were monomorphic and similar to those of the mother plant. This confirmed the true-to-type nature of the in vitro raised clones.

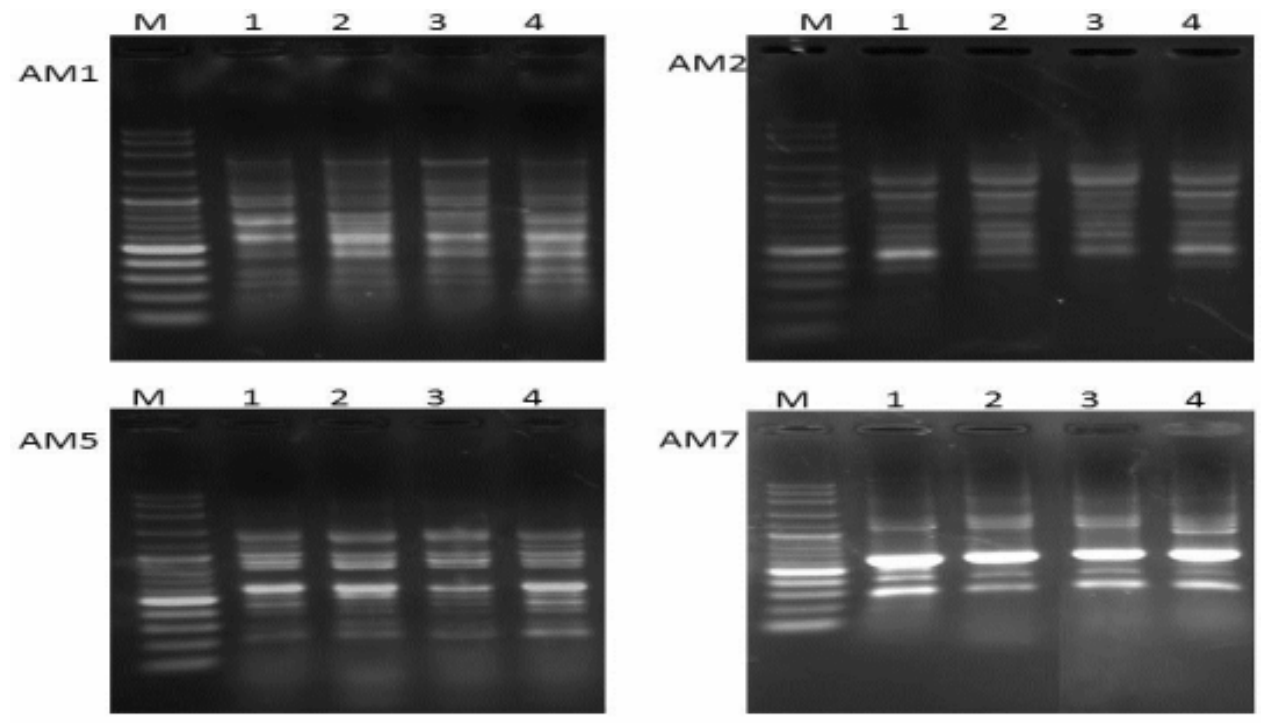

Fig. 2. SCoT amplification pattern obtained for the mother plant (lane 1) and micropropagated shoots cultures (lanes 2 - 4) generated by primers AM1, AM2, AM5 and AM7. M: DNA marker.

ISSR markers were also used to determine the somaclonal variations among the four samples (mother plant and those raised through tissue cultured). Four primers produced clear and reproducible bands (Fig. 3). A total of 14 bands were generated from the mother plant and the three from in vitro-raised clones with an average of 3.50 bands per primer. The number of scorable bands for each ISSR primer varied from 2 to 5 (Table 4). The ISSR data showed that the 
micropropagated plantlets conformed to their mother plant since $100 \%$ monomorphic bands were observed.

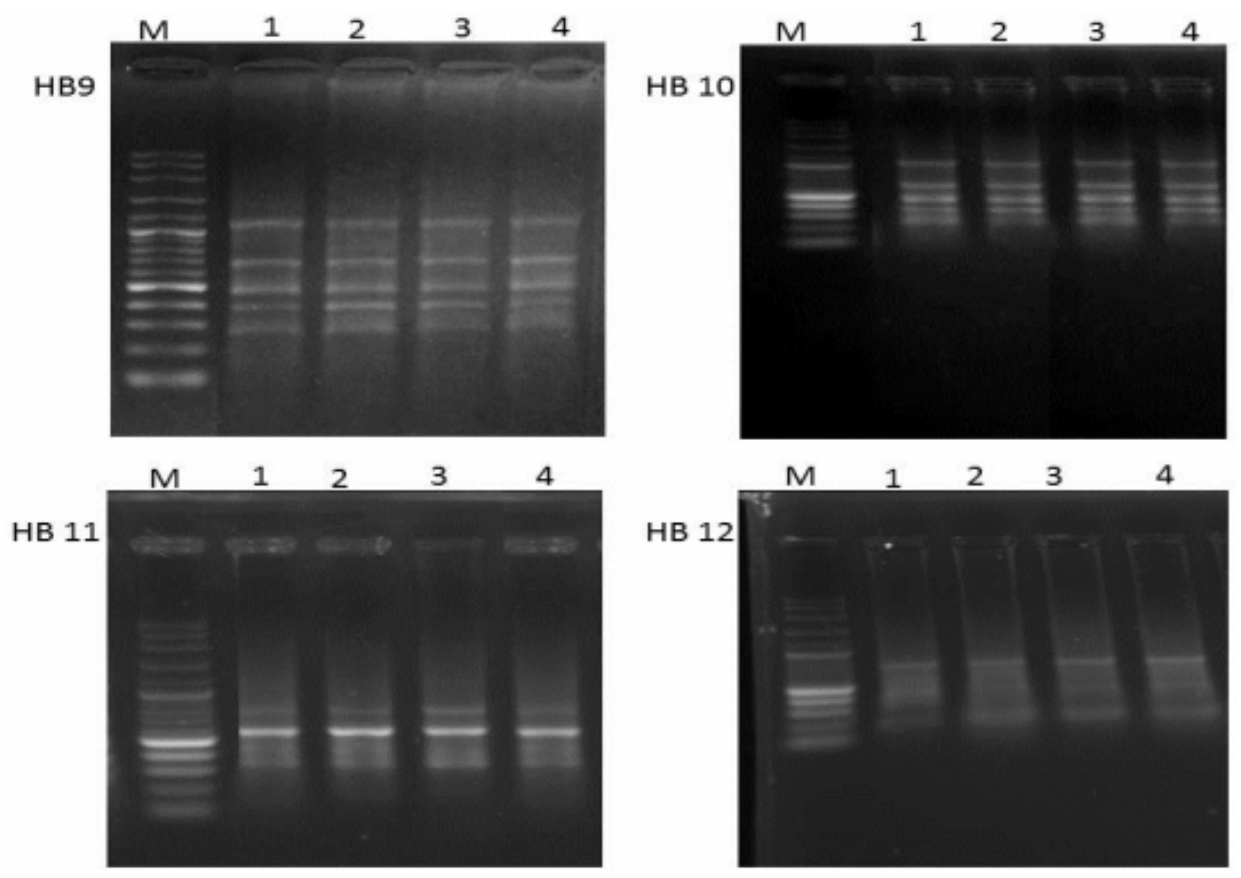

Fig. 3. ISSR amplification pattern obtained for the mother plant (lane 1) and micropropagated shoots cultures (lanes 2 - 4) generated by primers HB9, HB10, HB11 and HB12. M: DNA marker.

Since somaclonal variation is expected under tissue culture conditions, the genetic fidelity of the shoots formed and the protocol developed for mass propagation need to be ascertained. The presence or absence of variations during in vitro propagation depends upon the source of explants, levels of plant growth substances and the method of regeneration. Long term multiplication may often lead to somaclonal or epigenetic variations in micropropagated plants, thus questioning the very fidelity of their clonal nature. In the present study, the genetic stability of in vitro raised jojoba was assessed using SCoT and ISSR markers. The screened primers of SCoT and 4 ISSR primers produced clear reproducible and scorable bands. The number of bands generated per primer was greater in SCoT than ISSR. No polymorphism was detected during the SCoT or ISSR analysis of in vitro raised clones. Hence, this protocol can be successfully employed for the commercial multiplication of jojoba without much risk of genetic instability. Similar results were obtained by Kumar et al. (2011) during the clonal long-term (12 subcultures) micropropagated shoot cultures of jojoba 
using RAPD and ISSR markers. The amplified products were monomor-phic across all the selected micropropagated plants and were similar to the mother plant. Likewise, the absence of genetic variation using RAPD has been reported in micropropagated shoots of Pinus thunbergii (Goto et al. 1998) and in vitro regenerated turmeric (Salvi et al. 2001).

Table 4. Primers, their sequences and the number of bands of amplified fragments generated by SCOT and ISSR in both micropropagated and mother plants of jojoba.

\begin{tabular}{llccc}
\hline Primers & Sequence $\left(5^{\prime}-3^{\prime}\right)$ & $\begin{array}{c}\text { Total } \\
\text { number } \\
\text { of bands }\end{array}$ & $\begin{array}{c}\text { No. } \\
\text { monomorphic } \\
\text { bands }\end{array}$ & $\begin{array}{c}\text { No. } \\
\text { polymorphic } \\
\text { bands }\end{array}$ \\
\hline \multicolumn{2}{l}{ SCoT analysis } & & & \\
AM1 & CAACAATGGCTACCACCA & 5 & 5 & - \\
AM2 & ACGACATGGCGACCATCG & 5 & 5 & - \\
AM5 & CCATGGCTACCACCGCCA & 5 & 5 & - \\
AM7 & ACCATGGCTACCACCGAG & 4 & 4 & - \\
ISSR analysis & & & & - \\
HB9 & $(\mathrm{GT})_{6}$ GG & 5 & 5 & - \\
HB10 & $(\mathrm{GA})_{6}$ CC & 5 & 5 & - \\
HB11 & $(\mathrm{GT})_{6}$ CC & 2 & 2 & - \\
HB12 & $(\mathrm{CAC})_{3}$ GC & 2 & 2 & \\
\hline
\end{tabular}

\section{References}

Abud CD and Lugo MR (1983) In vitro propagation of jojoba [Simmondsia chinensis (Link.) Schneider] (in Spanish). Revista Chapingo 8(42): 39- 41.

Agrawal V, Prakash S and Gupta SC (2002) Effective protocol for in vitro shoot production through nodal explants of Simmondsia chinensis. Biologia Plantarum 45 (3): 449- 453.

Bashir MA, Rashid H and Anjum MA (2007a) In vitro shoot multiplication of six promising strains of jojoba (Simmondsia chinensis). Biotechnol. 6 (3): 309-315.

Bashir MA, Rashid H andAnjum MA (2007b) In vitro shoot initiation from nodal explants of jojoba (Simmondsia chinensis) strains. Biotechnol. 6: 165-174.

Chaturvedi HC and Sharma M (1989) In vitro production of cloned plants of jojoba (Simmondsia chinensis (Link.) Schneider) through shoot proliferation in long term culture. Plant Sci. 63: 199-207.

Collard BCY and Mackill DJ (2009) Start codon targeted (SCoT) polymorphism: A simple, novel DNA marker technique for generating gene-targeted markers in plants. Plant Mol. Biol. Rep. 27: 86-93. 
Elhag H, El-Olemy MM, Mossa JS, Tag-El-Din SS, Al-Zoghet MF and Al-Alsheikh AMA (1998) In vitro propagation of jojoba. Program Abstracts of Annual Conference on New Crops and New Uses: Biodiversity and Sustainability, 8-11 November, Phoenix, Arizona, USA.

Goto S, Thakur RC and Ishii K (1998) Determination of genetic stability in long-term micropropagated shoots of Pinus thunbergii Parl. using RAPD markers. Plant Cell Rep. 18:193-197.

Guo, ZH, Fu, KX, Zhang, XQ, Bai, SQ, Fan Y, Peng Y, Lin-Kai Huang LK, Yan, YH, Liu, W and Ma, X (2014) Molecular insights into the genetic diversity of Hemarthria compressa Germplasm collections native to southwest China. Molecules 19: 2154121559.

Hazarika BN (2003) Acclimatization of tissue cultured plants. Curr. Sci. 85:1704-1712.

Hegazi GA, Zayed MS, Salem HS and Ibrahim WM (2014) Effect of explant type and sequential subcultures on in vitro multiple shoots formation of jojoba. J. Appl. Environ. Biol. Sci. 4(4): 214-222.

Kacker NL, Joshi SP,Singh M and Solanki KR (1993) In vitro regeneration of female plants of Simmondsia chinensis (Link.) Schneider (Jojoba) using coppice shoots. Annals of Arid Zone 32(3): 175-177.

Khanam A, Rao YBN and Farook SA (1999) Standard in vitro protocol for high frequency mass micropropagation of jojoba (Simmondsia chinensis (Link.) Schneider). Adv. Plant Sci. 12: 361-366.

Kumar S, Mangal M, Dhawan AK and Singh N (2011) Assessment of genetic fidelity of micropropagated plants of Simmondsia chinensis (Link.) Schneider using RAPD and ISSR markers. Acta Physiol. Plant 33: 2541-2545.

Lee CW (1988) Application of plant biotechnology for clonal propagation and yield enhancement in jojoba. Proceedings of the 7th International Conference on Jojoba and its uses, 17 - 22 January 1988, Phoenix, Arizona, USA. pp. 102-111.

Llorente B and Apostolo NM (1998) Effect of different growth regulators and genotype on in vitro propagation of jojoba. New Zeal J. Crop Hort. Sci. 26: 55-62.

Llorente BE and Apóstolo NM (2013) In vitro propagation of jojoba. Methods in Molecular Biology 11013: 19-31.

Martin M, Sarmento D and Oliveira MM (2004) Genetic stability of micropropagated almond plantlets, as assessed by RAPD and ISSR markers. Plant Cell Rep. 23: 492496.

Meyghani H, Ghazvini RF and Hamidoghli Y (2005) Micropropagation from stem segments of salt tolerant jojoba seedlings. J. Korean Society for Horticul. Sci. 46(3): 183-187.

Mohasseb HA, El-Bahr MK, Adam ZM, Moursy HA and Solliman ME (2009) In vitro clonal propagation of jojoba (Simmondsia chinensis (Link) Schn.). Australian J. Basic and Appl. Sci. 3(4): 3128-3136.

Mousa MAA and Bakhashwain AAS (2014) Genotypic and growth regulator combination effects on in vitro nodal segments of jojoba (Simmondsia chinensis (Link). Life Sci. J. 11(4): 37-42. 
Mulpuri S, Muddanuru T and Francis G (2013) Start codon targeted (SCoT) polymorphism in toxic and non-toxic accessions of Jatropha curcas L. and development of a codominant SCAR marker. Plant Sci. 207: 117-127.

Niratker C, Preeti and Singh M (2015) Effect of different type of media on in vitro regeneration of mulberry (Morus indica): An economically important tree. Annals of Biol. Res. 6(1):22-26

Porebski S, Bailey LG and Baum BR (1997) Modification of a CTAB DNA extraction protocol for plants containing high polysaccharides and polyphenol component. Plant Mol. Biol. Reporter 15: 8-15.

Prakash S, Agrawal V and Gupta SC (2003) Influence of some adjuvants on in vitro clonal propagation of male and female jojoba plants. In Vitro Cellular and Developmental Biology Plant 39(2): 217- 222.

Prat L, Botti C and Palzkill D (1998) Rooting of jojoba cuttings: The effect of clone, substrate composition and temperature. Industrial Crops and Products 9(1): 47-52.

Reda AA (2003) An applicable protocol for jojoba (Simmondsia chinensis (Link.) Schneider) micropropagation J. Genet. Eng. and Biotechnol. 1(2): 317-326.

Roussos PA, Tolia-Marioli A, Pontikis CA and Kotsias D (1999) Rapid multiplication of jojoba seedlings by in vitro culture. Plant Cell Tiss. and Org. Cult. 57(2): 133- 137.

Salvi ND, George L and Eapen S (2001) Plant regeneration from leaf base callus of turmeric and random amplified polymorphic DNA analysis of regenerated plants. Plant Cell Tiss. and Org. Cult. 66: 113-119.

Sardana J and Batra A (1998) In vitro propagation of jojoba (Simmondsia chinensis): A plant of high potential. Adv. Plant Sci. 11: 143-146.

Satya P, Karan M, Jana S, Mitra S, Sharma A, Karmakar PG and Ray, DP (2015) Start codon targeted (SCoT) polymorphism reveals genetic diversity in wild and domesticated populations of ramie (Boehmeri anivea (L.) Gaudich.), a premium textile fiber producing species. Meta Gene. 3: 62-70.

Snedecor GW andCorchran WG (1967) Statistical methods. (Sixth Ed.), Iowa State University Press, Iowa.

Tyagi RK and Prakash S (2004) Genotypes and sex specific protocols for in vitro micropropagation and medium term conservation of jojoba. Biologia Plantarum 48(1): 19-23. 